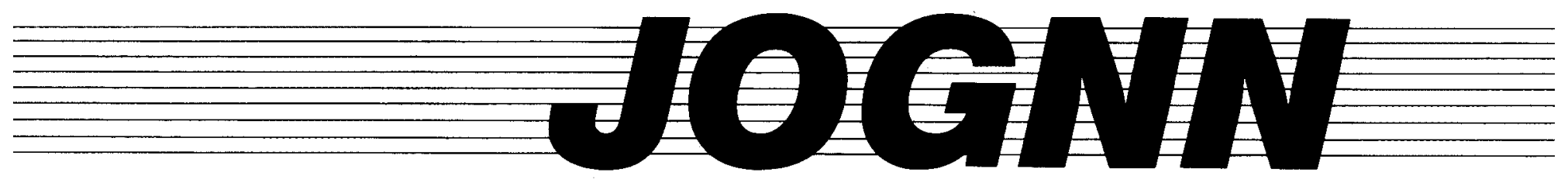

\title{
Perinatal Nurses' Knowledge and Attitudes about AIDS
}

\author{
NANCY A. PRINCE, RNC, MSN, BETTY J. BEARD, RN, PHD, SUZANNE LEWIS IVEY, RN, MS, \\ AND LULA LESTER, RN, MSN
}

Perinatal nurses were surveyed to determine their knowledge, attitudes, and fears concerning AIDS. Nurses' knowledge correlated positively with attendance at conferences and in-service programs. More than $85 \%$ of the respondents reported moderate to high fear of AIDS. No correlation was found between knowledge and self-reported fear scores. A discrepancy occurred between the nurses' beliefs that persons with AIDS deserve the same care as any other patient and the nurses' willingness to volunteer to care for these patients. Further research to test and evaluate coping strategies to help perinatal nurses care for mothers and newborns with AIDS must be conducted.

Perinatal nurses traditionally are exposed to many body fluids: blood, amniotic fluid, vernix, urine, stool, breast milk, and tears. The nurse's hands often are the first skin-to-skin contact the newborn experiences. But now acquired immunodeficiency syndrome (AIDS) is a concern, and health-care workers are wearing goggles and waterproof gowns as well as masks and gloves. Nurses are learning the skills of changing, pinning, injecting, taping, and bathing with gloved hands.

As of November 7, 1988, 6,524 women and 1,230 children-birth through 13 years-were diagnosed with AIDS. Eighty-four percent of the children diagnosed were under the age of five. ${ }^{1}$ Whereas the actual percentage of women and children with AIDS is low, the incidence of the syndrome is increasing most rapidly in women of childbearing age and, subsequently, in newborns. The number of women and children who test positive for human immunodeficiency virus (HIV+) is estimated to be even higher than those diagnosed with AIDS.

Accepted: March 1989

\section{LITERATURE REVIEW}

In 1987, Guinan and Hardy reported that of the 1,819 women with AIDS, the majority were of childbearing age. ${ }^{2}$ The transmission rate of these women and those HIV+ women who became pregnant and passed the virus to their infants was estimated to be as high as $65 \% .^{3}$ Perinatal transmission was responsible for about $80 \%$ of the reported pediatric cases of AIDS. ${ }^{4}$ The seroprevalence of HIV in populations of parturient women has been estimated using cord blood samples. ${ }^{5-7}$

The highest degree of seroprevalence $(2.35 \%)$ was found in large city hospitals in parturient women with histories of intravenous drug use. In contrast, only about one of 10,000 women in rural and suburban institutions with the lowest seroprevalence (.09\%) tested HIV+. In either case the perinatal nurse's risk of exposure appears to be low. However, the infectious, incurable, and always fatal risk of AIDS and the high body fluid contact in the perinatal setting offset any security that may be found in these numbers.

The National Centers for Disease Control documented cases of health-care workers infected with 
the AIDS virus through job-related exposure. ${ }^{8}$ Most of these cases were related to direct blood exposure, such as needle sticks with contaminated blood. Not known is how many, if any, perinatal nurses have become HIV+ after exposure in the workplace. The literature indicates that health-care workers are fearful and concerned about exposure to HIV+ patients or patients with AIDS..$^{9-15}$ Varying degrees of fear, anxiety, homophobia, and/or social stigmatization have been reported.

\section{As of November 7, 1988, 6,524 women and 1,230 children were diagnosed with AIDS.}

Few studies have exclusively reported nurses' attitudes toward patients with AIDS. In one study $80 \%$ of the nurses surveyed reported at least some fear of contracting AIDS in their workplaces. ${ }^{12}$ Fifty percent of these nurses reported family members were anxious about their caring for patients with AIDS. In another survey, conducted in a psychiatric setting, nurses expressed concern about contracting AIDS through casual contact. ${ }^{13}$ A poll conducted by Nursing Life showed that most of the 450 nurses responding were sympathetic to patients with AIDS; however, the nurses also expressed ambivalence about their duties and moral obligations to care for these patients. ${ }^{16}$ A survey of the staff in a large medical center hospital found greater fear among nurses working in high-acuity areas. ${ }^{17}$ Nearly half of the nurses in this medical center reported that they would seek a transfer if they had to care for patients with AIDS on a routine basis.

Caring for patients with AIDS or persons who are $\mathrm{HIV}+$ is perceived as a threat by many health-care workers. According to Lazarus's theory of coping and adaptation, threatening events are cognitively evaluated and depend upon the balance of power between demands and resources. ${ }^{18}$ Individuals respond to a threat most frequently with negatively toned emotions such as anxiety, fear, and anger. The degree of the response depends on the perception of the threat and the resources that are available to the individual. Coping strategies for dealing with threatening events may include direct action, inhibition of action, information seeking, intrapsychic processes, and turning to others for support. ${ }^{19}$

Responses to threats may be either positive or negative. Some individuals may move from the threat response to a challenge response by using one or more of the coping strategies. For example, the highly successful National Institutes of Health (NIH) campaign to recruit nurses for its AIDS ward used the challenge approach: "At NIH, a small team of nurses is fighting today's biggest health threat." ${ }^{20}$ This re- markably effective campaign elicited more than 360 responses from nurses. A plan of direct action, information giving, and team support was outlined.

\section{Caring for patients with AIDS or persons who are HIV+ is perceived as a threat by many health-care workers.}

Health-care workers are concerned about the risks involved in caring for patients who have AIDS or who test positive for HIV. Health-care providers may, as the literature suggests, respond negatively and perceive AIDS as a threat. The attitudes of perinatal nurses about AIDS must be determined to provide adequate information and resources and to promote positive coping mechanisms. Caring for persons with AIDS may then be viewed as a challenge instead of a threat.

\section{PURPOSE}

The purpose of this study was to explore perinatal nurses' knowledge and attitudes regarding AIDS and to measure their fear of AIDS in their work settings. The questions addressed were

1. What is the level of knowledge of perinatal nurses regarding AIDS?

2. What are perinatal nurses' fears and attitudes regarding AIDS?

3 . Is there a relationship between perinatal nurses' knowledge and attitudes about the care of patients with AIDS?

\section{METHODS}

\section{Sample}

The subjects of this study were 134 nurses working in perinatal departments of five midwestern hospitals. Hospitals were selected to represent both suburban and urban populations.

Participation was voluntary. Anonymity and confidentiality were assured because identification codes were not used. Completed questionnaires were sealed in envelopes by the subjects and returned to designated collection containers. Subjects were instructed in writing that completion of the questionnaires implied consent to participate.

\section{Instrument}

The questionnaire was a revision of an instrument previously used to assess nursing students' attitudes and knowledge concerning AIDS. ${ }^{21}$ Questions were added, dropped, or modified to reflect more current 
Table 1. Knowledge-Selected Questions ( $N=134)$

\begin{tabular}{|c|c|c|c|}
\hline Questions & True & False & Don't Know \\
\hline AIDS is characterized by a specific defect in the immune system. & $72 \% *$ & $22 \%$ & $5 \%$ \\
\hline The most common cause of death in AIDS patients is Pneumocyotis carnii pneumonia. & $77 \% *$ & $4 \%$ & $19 \%$ \\
\hline $\begin{array}{l}\text { HIV can be transmitted by infected persons who are asymptomatic. } \\
\text { If the mother is HIV+ the risk of an infant's developing AIDS-related illness may be as }\end{array}$ & $99 \% *$ & 0 & $1 \%$ \\
\hline high as $65 \%$. & $78 \% *$ & $2 \%$ & $19 \%$ \\
\hline Newborn infants who initially test HIV+ may, over time, test HIV-. & $16 \% *$ & $44 \%$ & $40 \%$ \\
\hline HIV has been found in human breast milk. & $55 \%{ }^{\star}$ & $5 \%$ & $40 \%$ \\
\hline Most of the children with AIDS were infected through perinatal transmission. & $50 \%{ }^{\star}$ & $31 \%$ & $19 \%$ \\
\hline
\end{tabular}

* Denotes correct answer.

knowledge about AIDS and to incorporate information more specific to the perinatal setting. Content validity was established by a panel of infection control and outpatient perinatal nurses. Seventeen questions designed to assess the nurses' knowledge about AIDS were included. The questions reflected information that was in the literature as of November 1987. In addition to the demographic questions, 29 variables related to respondents' attitudes, whereas two open-ended statements asked for subjects' responses. The instrument was pretested on $21 \mathrm{RNs}$. The responses of these nurses were not included in the final study.

\section{Data Analysis}

Participants reported as their primary areas of assignment labor and delivery (36\%); mother-infant (20\%); postpartum (15\%); newborn nursery $(10 \%)$; outpatient services (7\%); newborn intensive care (5\%); and other (7\%). All subjects who provided gender information were female $(N=133)$. One subject did not provide gender information. Ages ranged from 23 to 66 years $($ Mean $=36.8)$. Total years of experience as a perinatal nurse ranged from one to 31 (Mean $=12.7)$. More than half of the subjects $(63 \%)$ reported having attended conferences or in-service workshops on AIDS; $46 \%$ had cared for AIDS/HIV+ patients.

Data analysis was conducted using the statistical package for the social sciences (SPSS-X). The .01 probability level was chosen as significant for this study. Frequencies were done for all variables. Pearson correlation coefficients were done to determine relationships between background, knowledge, and attitude variables.

\section{RESULTS}

\section{Knowledge}

Most respondents (80\%) answered eight to 13 of the 17 knowledge questions correctly. A knowledge score was computed for each individual based on the 17 questions. The number of correct answers ranged from four to 16 , with a bimodal distribution of 11 and 12 correct. The use of a nonforced choice format reduced the guess factor. The "don't know" response for individual questions ranged from one percent to $40 \%$ (Table 1). Forty percent of respondents said that they did not know if HIV had been found in human breast milk. Forty percent of the nurses also said that they did not know if neonates who initially test HIV+ may, over time, test HIV-. For this same question, $44 \%$ of the nurses thought that they knew the answer when they did not.

Nearly all of the respondents (99\%) knew that HIV can be transmitted by infected persons who are asymptomatic. Most had some correct general knowledge about AIDS (Table 1). Seventy-eight percent of the nurses knew the risk of an infant's developing an AIDS-related illness if a mother was HIV+; however, only $50 \%$ of the nurses surveyed knew that most of the children with AIDS were infected through perinatal transmission.

Fifty-five percent of the nurses reported that they had obtained most of their information from professional sources. The remainder received their information from the media or friends.

\section{Fears and Attitudes}

A fear score was derived by asking nurses to note their fears of AIDS in their workplaces on a 10-point scale for which 0 equaled no fear and 9 equaled extreme fear. More than $85 \%$ indicated a moderate to high degree of fear (Figure 1). This fear extended to carrying the virus home to children, relatives, or friends for $35 \%$ of the respondents (Table 2). No significant correlation was found between knowledge and self-reported fear scores $(r=-.10)$.

More than half of the nurses (56\%) thought they were being exposed to HIV in their day-to-day activities. Forty-five percent favored mandatory screening 


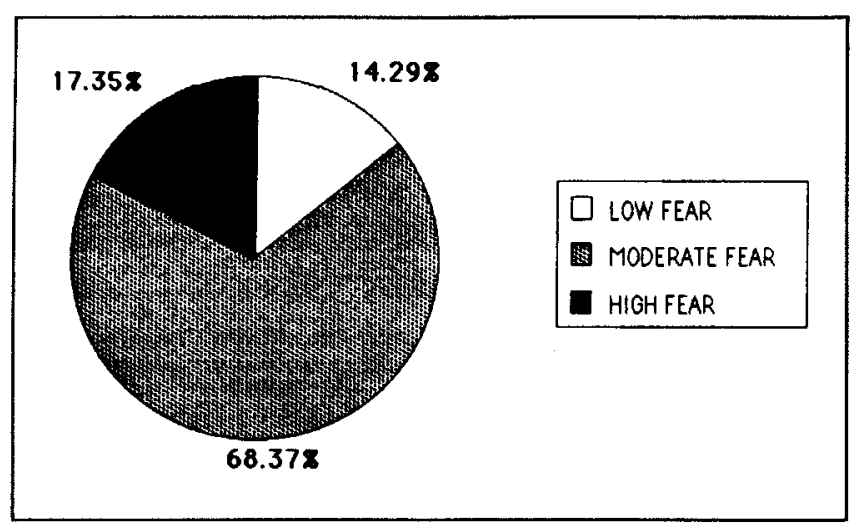

Figure 1. Fear of AIDS in workplace $(N=134)$.

of pregnant women for HIV, and nearly all (92\%) believed that health-care personnel should be informed that a patient is HIV positive. Ninety-seven percent thought that HIV+ neonates deserve the same care as any other newborn. However, when asked if they would volunteer to care for an AIDS patient, only $24 \%$ of the nurses said that they would.

\section{Further research must be done to determine the influence of knowledge on the nurse's willingness to care for AIDS/HIV+ patients.}

In regard to employment, $45 \%$ of the nurses thought all health-care workers should be tested for the presence of the HIV antibody. While $56 \%$ felt that nurses should not be fired for refusing to care for an HIV+ patient, $32 \%$ were neutral, and $12 \%$ favored termination of employment.

\section{Knowledge and Attitudes}

A positive relationship was demonstrated between a high knowledge level regarding AIDS and attendance at hospital in-service programs, professional conferences, and classroom sessions ( $r=.39$ ) (Table $3)$. An association also existed between high knowledge and having had the experience of caring for an AIDS or HIV+ patient $(r=.25)$.

Nurses scoring high in knowledge did not think that all health-care workers should be tested for the HIV antibody $(r=.35)$ or that all pregnant women should be screened for HIV $(r=.31)$. These nurses would care for an AIDS patient out of duty $(r=.23)$ and thought that nurses should be fired for refusing to care for an HIV+ patient $(r=.22)$.

No statistically significant correlation was found between knowledge and several other variables related to care of patients with AIDS (Table 3). For instance, no significant relationship was found between respondents' knowledge levels and beliefs that patients with AIDS or potential HIV+ newborns deserve the same care as other patients. Also, no significant relationship was demonstrated between level of knowledge and willingness to volunteer to care for an AIDS patient.

\section{DISCUSSION}

Results of the knowledge questionnaire demonstrated that many nurses either had incorrect or did not have basic information about perinatal AIDS. This suggests that continuing education programs may not always include facts related to AIDS in

Table 2. Perinatal Nurses' Fears and Attitudes about AIDS $(N=134)$

\begin{tabular}{|c|c|c|c|c|c|}
\hline Statement & $\begin{array}{l}\text { Strongly } \\
\text { Agree }\end{array}$ & Agree & Neutral & Disagree & $\begin{array}{l}\text { Strongly } \\
\text { Disagree }\end{array}$ \\
\hline \multicolumn{6}{|l|}{ I would fear carrying the AIDS virus home to my children, } \\
\hline In my day-by-day job activities, I feel that I may be & & & & & \\
\hline exposing myself to HIV. & $12 \%$ & $44 \%$ & $19 \%$ & $21 \%$ & $4 \%$ \\
\hline All pregnant women should be screened for HIV. & $18 \%$ & $27 \%$ & $23 \%$ & $22 \%$ & $10 \%$ \\
\hline $\begin{array}{l}\text { All health-care providers should be informed that a } \\
\text { patient is HIV+. }\end{array}$ & $61 \%$ & $31 \%$ & $4 \%$ & $2 \%$ & $2 \%$ \\
\hline $\begin{array}{l}\text { Potential HIV+ babies deserve the same care as any } \\
\text { other baby. }\end{array}$ & $49 \%$ & $47 \%$ & $1 \%$ & $2 \%$ & 0 \\
\hline I would volunteer to care for an AIDS patient. & $7 \%$ & $17 \%$ & $35 \%$ & $25 \%$ & $14 \%$ \\
\hline $\begin{array}{l}\text { All health-care workers should be tested for presence of } \\
\text { the HIV antibody. }\end{array}$ & $14 \%$ & $31 \%$ & $28 \%$ & $17 \%$ & $10 \%$ \\
\hline A nurse should be fired if she refuses to care for an & & & & & \\
\hline HIV+ patient. & $2 \%$ & $10 \%$ & $32 \%$ & $37 \%$ & $19 \%$ \\
\hline
\end{tabular}


Table 3. Correlation Coefficients between Knowledge and Selected Variables $(N=134)$

\begin{tabular}{l}
\hline \multicolumn{1}{c}{ Attitude Variable } \\
\hline Attendance at conferences, seminars, in-service \\
programs \\
Cared for patient with AIDS or one who was HIV \\
All health-care workers should not be tested for \\
presence of HIV antibody \\
All pregnant women should not be screened for HIV \\
A nurse should be fired if she refuses to care for an \\
HIV + patient \\
I would care for an AIDS patient because it is my duty \\
Patients with AIDS are entitled to the same care as \\
any other patient \\
I would volunteer to care for an AIDS patient \\
I would quit my job rather than care for an AIDS patient \\
I am afraid that my friends and family may avoid me if \\
they know that I am caring for an AIDS patient \\
A pregnant nurse should not be assigned to care for \\
HIV + patients \\
If a staff nurse knows that she is HIV + , she should \\
still be allowed to provide direct patient care on my \\
unit \\
I am afraid that I might contract AIDS in the routine \\
care of a patient with AIDS \\
\hline * $p<.001$.
\end{tabular}

women and children. When asked what additional information they would like regarding AIDS, nurses across the board requested ongoing and regular inservice programs focused on current and up-to-date information. The second area most commonly identified was a need for more information regarding transmission, risk factors, and protection of healthcare providers in regard to proper handling of body secretions.

Whereas a relationship was found between level of knowledge and having had the experience of caring for persons with AIDS, which variable preceded the other was not apparent from this study. In fact, no relationship was found between knowledge and willingness to volunteer to care for a woman or newborn with AIDS. Clearly, further research must be done to determine the influence of knowledge on the nurse's willingness to care for persons with AIDS.

A discrepancy occurred between nurses' beliefs that persons with AIDS deserve the same care as any other patient and the nurses' willingness to volunteer to care for these patients. This might be reflective of what Lazarus describes as one response to a threatening event-namely, inhibition of action.

Threatening situations are evaluated, according to Lazarus, as a balance between demands and re- sources. In response to open-ended questions, participants indicated concern about balancing the demand of caring for persons with AIDS with the resources available to provide this care. When asked to identify their greatest fears about AIDS in their workplaces, the nurses' comments centered on 1) fear of caring for AIDS or HIV+ patients and 2) not knowing about the AIDS or HIV diagnosis and exposing themselves in an emergency or failing to exercise care in a busy situation. Several nurses indicated they had cared for AIDS/HIV+ patients and only later learned the serostatus of the individuals.

The issue of confidentiality is a controversial one for both patients and health-care providers. Nurses in this study strongly indicated that all health-care providers have the right to know if patients are HIV+ and place this right above the patient's right to confidentiality.

Two limitations are noted in this study. The investigation was restricted to a small convenience sample of self-selected perinatal nurses in midwestern hospitals. Both urban and suburban hospital staff participated, thus increasing the representativeness of the sample.

Another limitation is noted in the knowledge questions regarding AIDS. Knowledge about this disease changes daily, and what was current several months ago may no longer be accurate today. Therefore, the study should be viewed as a cross section of what was known about AIDS on the day the survey was completed. Further, as with any self-report, respondents may convey attitudes that they feel are more desired by the researcher.

\section{IMPLICATIONS FOR PRACTICE}

Information about the transmission of AIDS and the treatment and care of persons with AIDS is changing rapidly. Much of this information is related to male populations. The perinatal nurse needs this information too, but with specific emphasis to her practice area of women and children. Staff in the perinatal area need to have an AIDS expert available to consult regarding areas of concern to perinatal practice. Even with prior knowledge most perinatal nurses will find the admitting of and caring for AIDS and HIV+ patients a source of at least moderate fear.

Expecting to diminish fear solely through education may be unrealistic. To expect no fear about AIDS may be unrealistic. Nevertheless, specific fears can and should be addressed. For instance, several nurses in this study expressed fears of making mistakes when rushed. Adequate staffing, necessary equipment, and practice time for changing long- 
standing habits (e.g., recapping needles) may increase a nurse's confidence level and decrease fear. Informal discussions can be scheduled to exchange thoughts and ideas. Other members of the healthcare team (e.g., pastoral care, social work, and infection-control personnel) may be invited to share their disciplines' expertise and provide support to the nursing staff. Fear also may be decreased by including nurses in formulating anticipatory policies and procedures before known HIV+ patients are admitted.

\section{A combination of education, support, and experience should increase nurses' willingness to care for AIDS/HIV+ patients.}

When a staff nurse is first assigned to care for an HIV+ patient, role modeling or guided experiences can be provided. A thoughtfully planned combination of education, support, and experience should increase nurses' willingness to care for HIV+ and AIDS patients.

\section{CONCLUSIONS}

With an estimated one million to 1.5 million persons in the United States harboring the AIDS virus, the likelihood of perinatal nurses encountering HIV+ positive mothers and newborns continues to grow. Fear of infection, the young age of AIDS patients, and the prolonged suffering and eventual death of the patient all add to the stress levels and the emotional responses of the caregivers. Further research to test and evaluate coping strategies to help perinatal nurses care for mothers and newborns with AIDS must be conducted.

In her review of the book The Primacy of Caring: Stress and Coping in Health and Illness, Baranowski states "for nursing, care is not a luxury or appendage of practice; it is the practice." ${ }^{22}$ Strategies to help perinatal nurses deal with the inevitable increase in AIDS and HIV+ mothers and newborns must focus not only on information giving but on support for the nurse whose essence is to care.

\section{REFERENCES}

1. Centers for Disease Control. Aids Weekly Surveillance Report. Atlanta: Centers for Disease Control, November 7, 1988.

2. Guinan, M.E., and A. Hardy. 1987. Epidemiology of AIDS in women in the United States. JAMA. 257:203942 .
3. Mendez, H., A. Willoughby, J. Hittelman, et al. 1988. Infants of HIV seropositive (SP) women and their seronegative (SN) controls. IV International Conference on AIDS Program and Abstracts (Book 2). Stockholm, Sweden: Stockholm International Fairs.

4. Centers for Disease Control. AIDS Weekly Surveillance Report. Atlanta: Centers for Disease Control, July 11, 1988.

5. Hoff, R., V.P. Berardi, B.J. Weiblen, L. Mahoney-Trout, M.L. Mitchell, and G.F. Grady. 1988. Seroprevalence of human immunodeficiency virus among childbearing women. $N$ Engl J Med. 318:525-29.

6. Kransinski, K., W. Borkowsky, D. Bebenroth, and T. Moore. 1988. Failure of voluntary testing for human immunodeficiency virus to identify infected parturient women in a high-risk population. $N$ Engl J Med. 318:185.

7. Landesman, S., H. Minkoff, S. Holman, S. McCalla, and O. Sijin. 1988. Serosurvey of human immunodeficiency virus testing programs of pregnant women. IAMA. 258:2701-3.

8. Centers for Disease Control. 1988. Update: Acquired immunodeficiency virus infection among health-care workers. MMWR. 37:229-34, 39

9. Barrett-Connor, E. 1984. Physician knowledge and concerns about AIDS. West J Med. 140:652-53.

10. Kelly, J.A., J.S. Lawrence, S. Smith, Jr., H.V. Hood, and D.J. Cook. 1987. Stigmatization of AIDS patients by physicians. Am J Public Health. 77:789-91.

11. Lewis, C., H. Freeman, and C. Corey. 1987. AIDS related competence of California's primary care physicians. Am J Public Health. 77:795-99.

12. Reed, P., T.N. Wise, and L.S. Mann. 1984. Nurses' attitudes regarding acquired immunodeficiency syndrome (AIDS). Nurs Forum. 21:153-56.

13. Rosse, R. 1985. Reactions of psychiatric staff to an AIDS patient. Am J Psychiatry. 142:523.

14. Searle, E.S. 1987. Knowledge, attitudes, and behavior of health professionals in relation to AIDS. Lancet. $1: 26-28$.

15. VanServellen, M.G., C.E. Lewis, and B. Leake. 1988. Nurses' responses to the AIDS Crisis: Implications for continuing education programs. The Journal for Continuing Education in Nursing. 19:4-8.

16. What our readers said about resuscitating a patient with AIDS. 1986. Nursing Life 6(5):23-24.

17. Blumenfield, M., P. Smith, J. Milazzo, and G. Wormser. 1987. Survey of attitudes of nurses working with AIDS patients. Gen Hosp Psychiatry. 9:652-53.

18. Lazarus, R.S., and R. Launier. Stress-related transactions between person and environment. In Perspectives in interactional psychology, edited by L.A. Pervin and M. Lewis. New York: Plenum, 1978.

19. Cohen, F., and R.S. Lazarus. Coping and adaptation in health and illness. In Handbook of health, health care, and health professions, edited by D. Mechanic. New York: The Free Press, 1983.

20. Herrin, A. May 24, 1988. Idealism overrides fears. Detroit Free Press.

21. Lester, L., and B. Beard. 1988. Nursing students' attitudes about AIDS. J Nurs Educ, 27:399-404.

22. Baranowski, M.V. 1988. Review of The Primacy of Caring: Stress and Coping in Health and Illness by P. Brenner and J. Wrubel. Image 20(2):113-14. 
Address for correspondence: Nancy A. Prince, RN, 1516 Bardstown Trail, Ann Arbor, MI 48105-2876.

Nancy A. Prince is an assistant professor of matemal-child health nursing at Eastern Michigan University in Ypsilanti and a staff nurse in obstetrics at Catherine McAuley Health Center in Ann Arbor. Ms. Prince is a member of NAACOG and Sigma Theta Tau.
Betty $\mathrm{J}$. Beard is an associate professor of maternal-child health nursing at Eastern Michigan University. Dr. Beard is a member of NAACOG, the American Nurses' Association, and Sigma Theta Tau.

Suzanne Lewis Ivey is an assistant professor of nursing at Eastern Michigan University. She is a member of the National League of Nursing and Sigma Theta Tau.

Lula Lester is an assistant professor of nursing at Eastern Michigan University and clinician I on the cardiac stepdown unit at the University of Michigan Hospitals. Ms. Lester is a member of Sigma Theta Tau.

\section{nagcon Newsletter}

Keeping up with the latest developments in obstetric, gynecologic, and neonatal (OGN) nursing can be a full-time job. Let NAACOG, the organization for obstetric, gynecologic, and neonatal nurses, do the work for you. Subscribe to the NAACOG Newsletter and you will receive

- in-depth reports on the latest trends in OGN nursing practice

- personal profiles of the women and men shaping the future of OGN nursing

- details on the latest resources available to OGN nurses and their clients

- facts about new OGN technology and treatment recommendations

- notes on legislation and policy making affecting OGN nursing

- updates on NAACOG activities

- notices of upcoming professional meetings

- job listings from across the country

- and much, much more

To order, complete the form below and mail as directed. Don't miss another issue. Subscribe today!

One-year subscriptions to the NAACOG Newsletter (12 issues) are available for $\$ 20.00$. To start receiving your newsletters, complete the form below and mail it with your check or money order (made payable to NAACOG) to NAACOG, Communications Department, 409 12th Street, S.W., Washington, DC 20024.

\section{Subscriber Information}

\section{Name}

\section{Address}
City
State
Zip Code

To receive a free sample copy of the NAACOG Newsletter, write to T. Lynch, NAACOG, Communications Department, 409 12th Street, S.W., Washington, DC 20024. 